Article

\title{
Evaluation of Policy Influence on Long-Term Indoor Air Quality in Emperor Qin's Terra-Cotta Museum, China
}

\author{
Hua Li ${ }^{1,2,3}$, Tafeng Hu ${ }^{1, *}$, Wenting Jia ${ }^{1}$, Junji Cao ${ }^{1,4, *}$, Suixin Liu ${ }^{1}$, Rujin Huang ${ }^{1}$, Tao Ma 5 \\ and $\mathrm{Na} \mathrm{Xi}{ }^{3}$
}

1 Key Lab of Aerosol Chemistry \& Physics, Institute of Earth Environment, Chinese Academy of Sciences, Xi'an 710061, China; E-Mails: 1lhh669@sohu.com (H.L.); jiawt@ieecas.cn (W.J.); 1sx@ieecas.cn (S.L.); Rujin.Huang@psi.ch (R.H.)

2 University of Chinese Academy of Sciences, Beijing 100049, China

3 Key Scientific Research Base of Ancient Polychrome Pottery Conservation, SACH, Emperor Qin Shihuang’s Mausoleum Site Museum, Xi’an 710600, China; E-Mail: littlena@163.com

4 Institute of Global Environmental Change, Xi'an Jiaotong University, Xi' an 710049, China

5 Shaanxi Institute for the Preservation of Cultural Heritage, Xi'an 710075, China; E-Mail: mt2100@qq.com

* Authors to whom correspondence should be addressed; E-Mails: hutf@ieecas.cn (T.H.); cao@loess.llqg.ac.cn (J.C.); Tel.: +86-29-6233-6273; Fax: +86-29-6233-6234.

Academic Editors: Guohui Li and Robert W. Talbot

Received: 22 January 2015 / Accepted: 19 March 2015 / Published: 3 April 2015

\begin{abstract}
Long-term measurement results of indoor air quality (IAQ) from 1989 to 2013 inside Pit No. 1, the largest display hall in Emperor Qin's Terra-cotta Museum (QTM), were used to evaluate the effectiveness of measures for conservation environment improvement of antiques. By comparing the results of sampling campaigns in 2013 with databases in 1989, 2004-2005, 2006-2007 and 2011, seasonal and inter-annual variation in microclimate, aerosol chemical compositions and gaseous pollutant concentrations were incorporated in estimating the probable influences of the management of the surroundings, tourist flow, excavation and restoration tasks and renovation and/or new construction work on IAQ in the QTM. After the implementation of the environmental policies in 1990s, a significant decrease of indoor particulate matter mass for the QTM was quantified. The mass concentrations of summer TSP decreased from $540.0 \mu \mathrm{g} \cdot \mathrm{m}^{-3}$ in 1994 to $172.4 \mu \mathrm{g} \cdot \mathrm{m}^{-3}$ in 2004, as well as the winter TSP decreased from $380.0 \mu \mathrm{g} \cdot \mathrm{m}^{-3}$ in 1994 to $312.5 \mu \mathrm{g} \cdot \mathrm{m}^{-3}$ in 2005. The mass concentrations of summer $\mathrm{PM}_{2.5}$ decreased from $108.4 \mu \mathrm{g} \cdot \mathrm{m}^{-3}$ in 2004 to
\end{abstract}


$65.7 \mu \mathrm{g} \cdot \mathrm{m}^{-3}$ in 2013 , as well as the winter $\mathrm{PM}_{2.5}$ decreased from $242.3 \mu \mathrm{g} \cdot \mathrm{m}^{-3}$ in 2005 to $98.6 \mu \mathrm{g} \cdot \mathrm{m}^{-3}$ in 2013 . However, it is noted that potential hazards due to the fluctuant microclimate conditions, gaseous and secondary particulate acidic species in indoor air should still be considered to ensure the long-term preservation and conservation of the museum's artifact collection.

Keywords: indoor air quality; environmental policy; terra-cotta warriors; museum

\section{Introduction}

Cultural heritage is an irreplaceable witness of human civilization and is vulnerable to both natural disasters and anthropogenic pollution. Air quality in museums is critical to the preservation and conservation of rare antiquities [1-7], with damage from air pollution being firstly reported in the middle of the 19th century at the British Art Gallery [3]. Since the 1990s, the microclimate in museums and airborne pollutants originating from indoor activities and/or penetration from outdoors have been of increasing concern in Europe [5,8-11] and the United States [4,12]. In China, particulate pollution due to rapid industrialization and urbanization has become a serious environmental problem at the regional scale [13]. Thus, the surrounding environment was also considered to evaluate the potential soiling and weathering hazards from outdoor particulate matter for statues inside naturally-ventilated museums [14-19].

In 1974, a huge burial pit with thousands of terra-cotta warriors and horses was discovered and subsequently excavated about $1.5 \mathrm{~km}$ to the east of Emperor Qin Shihuang's mausoleum. The largest display hall of the museum, namely Pit No. 1 (Pit 1), was built over more than 1200 terra-cotta sculptures in the archaeological pit and has been opened to the public since 1979. Since then, more and more tourists have visited the museum for the fabulous terra-cotta army in full battle array in Pit 1 . In 1980, the visitor number was 1.04 million, the maximum number reaching 5.27 million in 2011, which stimulated the rapid growth of transportation and tourism infrastructure around the museum. Moreover, the Emperor Qin's Terra-cotta Museum (QTM) museum is located about $30 \mathrm{~km}$ east of Xi'an, a city of 8.46 million people with high coal consumption and intensive construction work. Similar to most of the megacities in China, Xi' an is experiencing extreme air pollution problems with the dense population, rapid economic growth and urbanization [20]. Long-term monitoring records from 2002 to 2011 also showed that the annual average of ambient $\mathrm{PM}_{2.5}$ decreased with a speed of $4 \mathrm{ug} \cdot \mathrm{m}^{-3} \mathrm{y}^{-1}$ [21]. The museum is also surrounded by agricultural fields in which biomass burning and suspended soil dust are prominent. Therefore, a series of measures have been adopted to improve the conservation environment in the QTM since the 1990s, including continuous vegetation in landscape maintenance, energy innovation and relocation of the parking lot and surrounding factories [22].

The earliest indoor environment investigation in the QTM was accomplished in 1989 [23] in which the summer and winter microclimate conditions in Pit 1 were recorded. Subsequently, several respective monitoring and sampling campaigns initiated in 1993 [23], 2004 [17], 2006 [24] and 2011 [25] have incorporated gaseous pollutants and particulate matters into the dataset of indoor air quality in Pit 1 . In this study, updated information on the current status of indoor air quality and its long-term variation in 
the QTM was provided to evaluate the influence of the environmental policy implemented since the 1990 s.

\section{Methodology}

\subsection{Indoor and Outdoor Sampling}

The Pit 1 display hall covers a total area of $14,269 \mathrm{~m}^{2}$ with a hangar-like steel-frame vault to shield the statues from direct solar illumination and precipitation. Most of the wide windows in Pit 1 remain open all year long. There is no heating, air conditioning, mechanical ventilation or filtration system equipped in Pit 1. As shown in Figure 1, the indoor sampling site was placed in the restoration zone at the rear of Pit 1 . All of the samplers and real-time analyzers were placed about $1.0 \mathrm{~m}$ above the ground. The outdoor site was located on the roof of a two-story office building, about $10 \mathrm{~m}$ above the ground and $150 \mathrm{~m}$ in the south of the Pit 1.

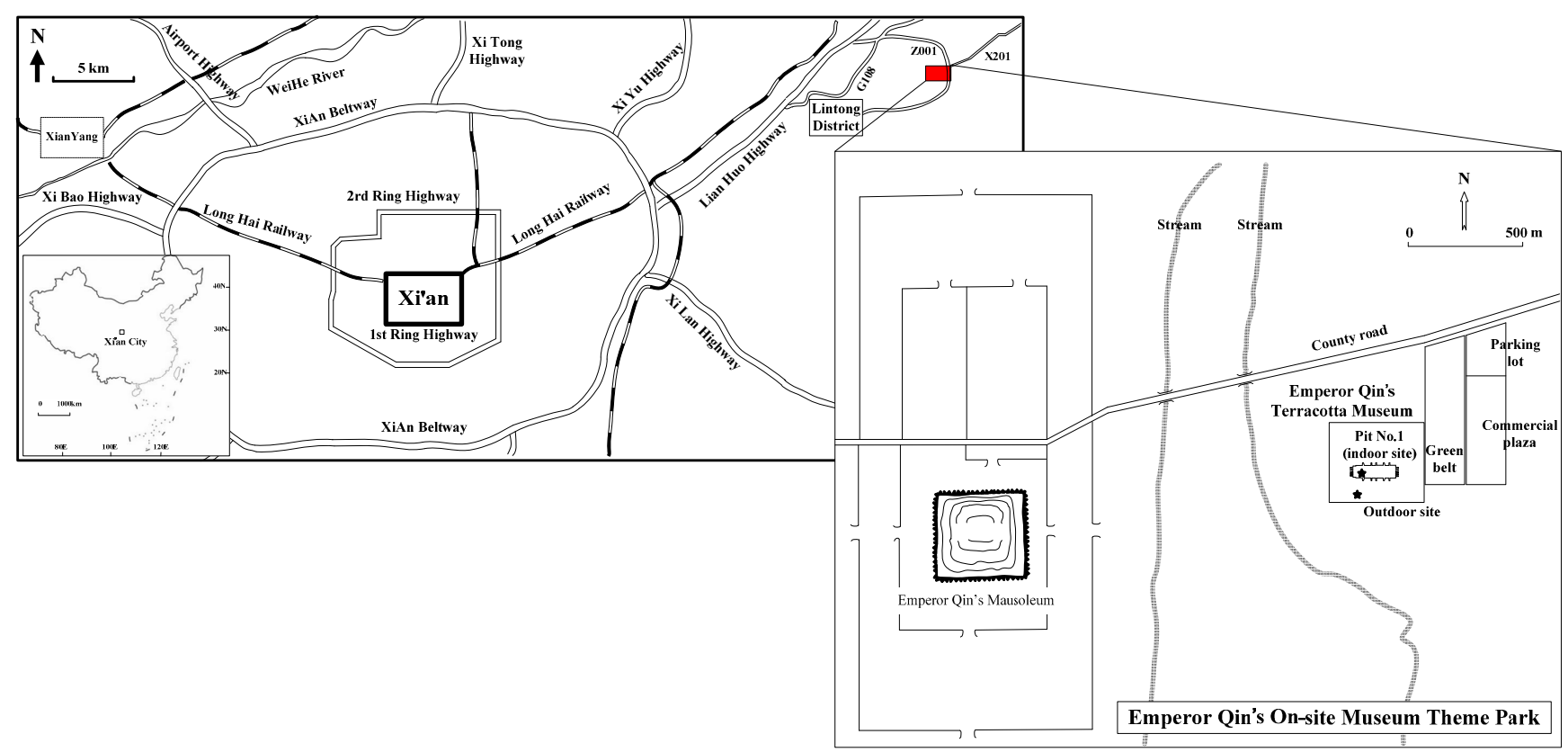

Figure 1. Locations of the sampling sites inside and outside the Pit No. 1 Display Hall of Emperor Qin's Terra-cotta Museum in Xi'an, China.

$\mathrm{PM}_{2.5}$ samples were collected for 24 hours at a $5-\mathrm{L} \cdot \mathrm{min}^{-1}$ flow rate with a mini-vol portable sampler (Airmetrics, Springfield, OR, USA) onto 47-mm quartz-fiber filters (Whatman, Clifton, NJ, USA) from 6-19 August in summer to 27 November-10 December in winter, 2013. The quartz-fiber filters were pre-heated at $900{ }^{\circ} \mathrm{C}$ for $3 \mathrm{~h}$ to remove the residual carbon before the sampling. The sampler flow calibration was performed using a calibration device (Bios Definer, 220H, 300-30,000 sccm) every month. Gaseous pollutants, including $\mathrm{NO}_{2}$ and $\mathrm{SO}_{2}$, were measured using portable electrochemical analyzers (Models 4150 and 4240, Interscan Corporation, Chatworth, CA, USA) at 1-min interval. The analyzers was zeroed before and every 4 hours during each sampling campaign with the C-12 zero filter (activated carbon), and their calibrations were accomplished before and after each sampling campaign, with volumetrically diluting (Sabio 4010 Gas Dilution Calibrator) the $\mathrm{NO}_{2} /$ nitrogen and $\mathrm{SO}_{2} /$ nitrogen gas standard with zero air (Sabio 1001 Zero Air Source). Two portable Q-Trak Plus indoor air quality 
(IAQ) monitors (Model 7565, TSI Inc., Shoreview, MN, USA) were used to obtain the 1-min average $\mathrm{CO}_{2}$ concentrations, air temperature $(\mathrm{T})$ and relative humidity $(\mathrm{RH})$ records indoors and outdoors, respectively. The Q-Trak $\mathrm{CO}_{2}$ calibrations were accomplished before and after each sampling campaign, by volumetrically diluting (Sabio 4010 Gas Dilution Calibrator) $\mathrm{CO}_{2} /$ nitrogen gas standard, and its temperature and relative humidity calibration were conducted by TSI in Beijing.

\subsection{Sample Analysis}

Quartz-fiber filters were gravimetrically analyzed for $\mathrm{PM}_{2.5}$ mass concentrations using an electronic microbalance with 1- $\mu$ g sensitivity (Model MC5, Sartorius, Göttingen, Germany) after 24-hour equilibration at a temperature between $20{ }^{\circ} \mathrm{C}$ and $23{ }^{\circ} \mathrm{C}$ and $\mathrm{RH}$ between $35 \%$ and $45 \%$. Each filter was weighed at least three times before and after samplings, and the net mass was obtained by subtracting the difference between the averaged pre- and post-sampling weights. Daily, after the balance is turned on, calibration/adjustment was carried out using an internal check weight and an external check weight (with 2 sets of standard weights, $100 \mathrm{mg}$ and $200 \mathrm{mg}$ ).

Concentrations of elemental K, Ca, Ti, Cr, Mn, Fe, Ni, Zn, As, Br, Mo, Cd and Pb collected on the filters were determined by energy-dispersive X-ray fluorescence spectrometry (Model Epsilon 5, PANalytical B.V., Almelo, The Netherlands). The X-ray source is a side-window X-ray tube with a gadolinium anode, operated at an accelerating voltage of 25 to $100 \mathrm{kV}$ and a current of 0.5 to $24 \mathrm{~mA}$. A spectrum of X-ray counts versus photon energy was acquired during analysis, with the individual peak energies matching to specific elements and peak areas corresponding to elemental concentrations. The ED-XRF spectrometer was calibrated with thin-film standards obtained from MicroMatter Co. (Arlington, WA, USA). In total, 15 elements (i.e., S, Cl, K, Ca, Ti, Cr, Mn, Fe, Ni, Zn, As, Br, Mo, Cd and $\mathrm{Pb}$ ) were determined [26].

One-fourth of each filter sample was removed and extracted in $10 \mathrm{~mL}$ of high-purity water. Nine ionic species $\left(\mathrm{NH}_{4}{ }^{+}, \mathrm{K}^{+}, \mathrm{Na}^{+}, \mathrm{Mg}^{2+}, \mathrm{Ca}^{2+}, \mathrm{NO}_{3}{ }^{-}, \mathrm{SO}_{4}{ }^{2-}, \mathrm{Cl}^{-}, \mathrm{F}^{-}\right)$were measured by ion chromatography (Model DX600, Dionex Inc., Sunnyvale, CA, USA) [27]. An ACS12 column $(150 \times 4 \mathrm{~mm})$ and an AS14 column $(150 \times 4 \mathrm{~mm})$ were used for cation and anion analysis, respectively. Field blank levels were averaged and subtracted, and standard deviations were propagated to the measurement precisions. Method detection limits (MDLs) were $4.6 \mu \mathrm{g} \cdot \mathrm{L}^{-1}$ for $\mathrm{Na}^{+}, 4.0 \mu \mathrm{g} \cdot \mathrm{L}^{-1}$ for $\mathrm{NH}_{4}^{+}, 10.0 \mu \mathrm{g} \cdot \mathrm{L}^{-1}$ for $\mathrm{K}^{+}$, $\mathrm{Mg}^{2+}$ and $\mathrm{Ca}^{2+}, 0.5 \mu \mathrm{g} \cdot \mathrm{L}^{-1}$ for $\mathrm{F}^{-}, \mathrm{Cl}^{-}$and $\mathrm{Br}^{-}, 15 \mu \mathrm{g} \cdot \mathrm{L}^{-1}$ for $\mathrm{NO}_{2}{ }^{-}$and $\mathrm{NO}_{3}{ }^{-}$and $20 \mu \mathrm{g} \cdot \mathrm{L}^{-1}$ for $\mathrm{SO}_{4}{ }^{2-}$. Ten percent of the samples was submitted for replicate analyses. Standard reference materials produced by the National Research Center for Certified Reference Materials (Beijing, China) were analyzed for quality control and assurance purposes. All of the reported ion concentrations were corrected for field blanks, i.e., filters brought to the field and installed in the samplers, but for which no air was pumped. The experimental uncertainties were \pm 0.04 for $\mathrm{F}^{-}, \mathrm{NO}_{3}{ }^{-}$and $\mathrm{SO}_{4}{ }^{2-}, \pm 0.03$ for $\mathrm{Ca}^{2+}$, \pm 0.02 for $\mathrm{Cl}^{-}$and $\mathrm{Br}^{-}, \pm 0.01$ for $\mathrm{NO}_{2}{ }^{-}, \mathrm{NH}_{4}{ }^{+}, \mathrm{K}^{+}$and $\mathrm{Mg}^{2+}$, and \pm 0.004 for $\mathrm{Na}^{+}$.

A punch of $0.5 \mathrm{~cm}^{2}$ from each quartz filter was analyzed for organic carbon (OC) and elemental carbon (EC) concentrations by the IMPROVE A thermal/optical protocol method using a DRI Model 2001 thermal/optical carbon analyzer (Atmoslytic Inc., Calabasas, CA, USA). The analyzer was calibrated with known quantities of $\mathrm{CH}_{4}$ every day. Replicate analyses were performed at the rate of one per group of 10 samples. Sixteen blank filters were also analyzed and the sample results were corrected by the average of the blank concentrations [28]. 


\section{Results and Discussion}

\subsection{Environmental Policy in the QTM}

Aiming to improve the landscape and air quality in the QTM, the largest on-site museum in China, environmental policies and measures have been continuously developed and strengthened since the 1990s. An afforestation plan started in 1990, focusing on the continuous improvement of the vegetation in the yards and landscape maintenance each year. In 2002, under the support of an energy innovation plan of the QTM, the coal-fire boiler for office and staff dormitory heating in wintertime (coal consumption 1200 ton/y) was replaced by an electric boiler. During a reconstruction project from 2002 to 2004 , the adjacent parking lot was relocated to $\sim 1 \mathrm{~km}$ away from the east gate of the QTM and separated by a $0.2-\mathrm{km}^{2}$ greenbelt. In 2006, the Emperor Qin Shihuang's Mausoleum Site Museum Theme Park project was initiated to merge the QTM with the mausoleum, which is located $1.5 \mathrm{~km}$ to the west. As a part of the first stage of preparation work, 26 tourist souvenir factories and 1002 residential dwellings dispersed between the QTM and the Mausoleum have been relocated before 2007. Although most of those implemented environmental measures were to reduce the burden of outdoor air pollution coming from the emission of fossil fuel combustion and re-suspension of road dust and fugitive soil, the decrease of ambient aerosol in the outdoor environment may lower indoor particle levels due to infiltration through natural ventilation in Pit 1.

However, since the QTM opened to the public in 1979, there also appeared some potential sources of indoor particulate matters, including outdoor construction work and indoor activities. Besides several excavation and restoration campaigns and routine indoor cleaning, the infrastructures of the QTM have been intermittently expanded to satisfy the rapid growth of tourist flow. From 1992 to 1993, more than half of the terra-cotta warriors and horses in the front part of the Pit 1 display hall were rearranged into the full battle array between rammed walls after the cleaning of the brick ground and rammed walls. From 2002 to 2003, a conference hall with an area of $3998 \mathrm{~m}^{2}$ was built on the south of Pit 1 . From 2004 to 2005 , a commercial plaza was constructed adjacent to the greenbelt. There have been three excavation campaigns (1974, 1985 and 2009) since the burial pit was discovered. The third campaign started in 2009, and the excavation work was accomplished in 2011, followed by long-term on-site restoration work at the rear of Pit 1. Alcoholic solvents and resin adhesives were frequently employed for antique cleaning, repair and restoration. Before 2010, only two entrance and exit gates of the display hall were opened during the opening hours of the museum. Since 2010, all seven gates were available under increasing pressure from visitor numbers.

\subsection{Microclimate}

Records of microclimate conditions during the sampling campaigns from 1989 to 2013 are listed in Table 1. The average indoor air temperature increased by $2.6{ }^{\circ} \mathrm{C}$ in winter and $6.9{ }^{\circ} \mathrm{C}$ in summer, in accordance with the tendency for outdoor air temperature in Xi' an city [29], as well as the indoor $\mathrm{RH}$ decreased by $26.1 \%$ in winter and $12.1 \%$ in summer from 1989 to 2013 . Although the fluctuations of indoor temperature during each sampling campaign varied from $5.3^{\circ} \mathrm{C}$ to $18.2{ }^{\circ} \mathrm{C}$ in winter and $9.0^{\circ} \mathrm{C}$ to $17.7^{\circ} \mathrm{C}$ in summer, the seasonal variation of indoor temperature remained at a high level, with the average reaching $23.4^{\circ} \mathrm{C}$ due to the natural ventilation in Pit 1 . The fluctuant relative humidity was 
found during each sampling campaign with an average of $35.2 \%$ in winter and $25.3 \%$ in summer. The seasonal variation of indoor relative humidity was observed ranging from $27.9 \%$ to $58.5 \%$ with an average of $43.5 \%$. Those fluctuations of microclimate conditions, including short-term fluctuations in each sampling campaign, seasonal and annual variations, are far beyond the permissible fluctuation limits in controlled museums [30] and may bring potential weathering hazards to the statues.

Table 1. Winter and summer temperature and relative humidity records inside the Pit No. 1 Display Hall of Emperor Qin's Terra-cotta Museum during several sampling campaigns from 1989 to 2013.

\begin{tabular}{ccccccccc}
\hline & $\mathbf{T}\left({ }^{\circ} \mathbf{C}\right)$ & \multicolumn{3}{c}{ RH (\%) } & & Reference \\
\hline & Avg. \pm S.D. & Max. & Min. & Avg. \pm S.D. & Max. & Min. & \\
Winter & & & & & & & \\
November-December 2013 & $7.3 \pm 1.9$ & 13.2 & 2.8 & $40.9 \pm 3.3$ & 57.6 & 20.0 & This study \\
December 2006 & $4.9 \pm 5.5$ & 16.3 & -1.9 & $53.5 \pm 18.1$ & 68.4 & 22.8 & {$[24]$} \\
January 2005 & $2.3 \pm 1.8$ & 5.3 & 0 & $64.0 \pm 7.8$ & 78.0 & 48.0 & {$[17]$} \\
December 1989 & $4.7 \pm 3.1$ & 6.6 & -2.0 & $67.0 \pm 10.8$ & 80.1 & 52.6 & {$[23]$} \\
Summer & & & & & & & \\
August 2013 & $30.7 \pm 2.2$ & 37.5 & 23.2 & $59.9 \pm 3.2$ & 78.5 & 43.0 & This study \\
August 2006 & $32.2 \pm 5.7$ & 40.3 & 22.6 & $45.2 \pm 1.9$ & 51.3 & 40.2 & {$[24]$} \\
August 2004 & $26.2 \pm 3.5$ & 32.4 & 21.9 & $70.8 \pm 7.3$ & 80.0 & 56.0 & {$[17]$} \\
August 1989 & $23.8 \pm 2.8$ & 31.2 & 22.2 & $72.0 \pm 11.8$ & 84.5 & 53.9 & {$[23]$} \\
\hline
\end{tabular}

The unstable microclimate conditions in the 2013 sampling campaigns are also illustrated in Figure 2, including summer and winter diurnal fluctuations in air temperature, relative humidity and concentrations of carbon dioxide inside and outside Pit 1 . The huge building covering Pit 1 is only to shield the statues from direct solar illumination and precipitation. In this naturally-ventilated display hall, it can be found that the fluctuations of indoor air temperature and relative humidity followed those outdoors in the respective summer and winter sampling campaign (Figure 2). The variation of daily average indoor temperature and $\mathrm{RH}$ between winter and summer reached $23.4{ }^{\circ} \mathrm{C}$ and $19.0 \%$, implying a potential hazard for the statues from the dramatic seasonal fluctuation of the microclimate conditions. Since the excavation in the 1970s, the priceless and irreplaceable statues have suffered frequent microclimate changes for more than 30 years of exposure in the display hall.

Indoor $\mathrm{CO}_{2}$ varied from $432 \mathrm{ppm}$ to $701 \mathrm{ppm}$ with an average of $511 \mathrm{ppm}$ in summer and from $486 \mathrm{ppm}$ to $586 \mathrm{ppm}$ with an average of $518 \mathrm{ppm}$ in winter. Outdoor average $\mathrm{CO}_{2}$ concentration is $351 \mathrm{ppm}$ during summer and $426 \mathrm{ppm}$ during winter. The peak of excess indoor $\mathrm{CO}_{2}$ in Figure 3 indicates obvious influences from visitors and museum staff activities. 


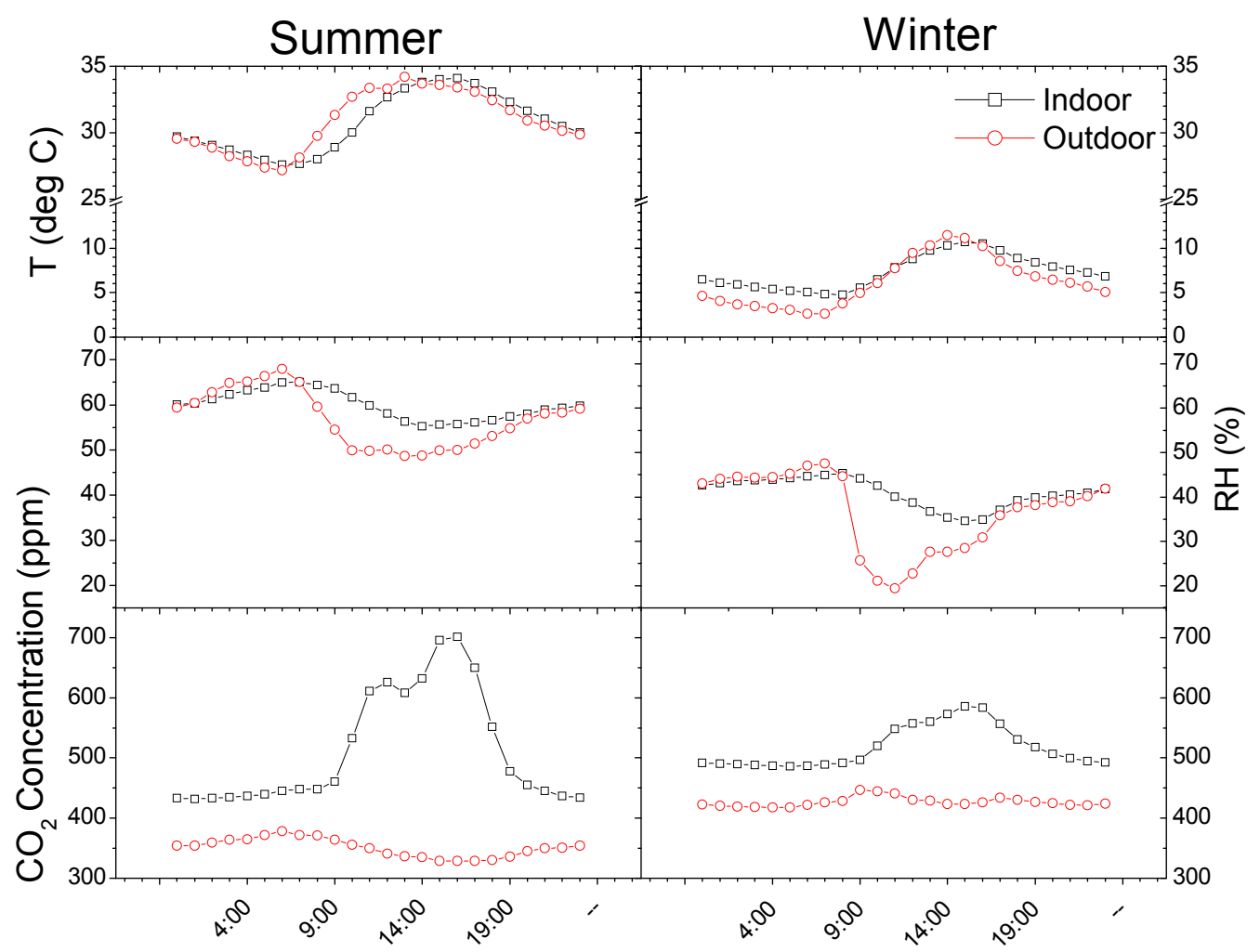

Date

Figure 2. Fourteen-day averaged diurnal fluctuations in air temperature, relative humidity and concentrations of carbon dioxide inside and outside Pit No. 1 Display Hall of Emperor Qin's Terra-cotta Museum in the summer and winter sampling campaigns in 2013, respectively.

\subsection{Chemical Compositions of PM}

The mass concentrations and mass balance of $\mathrm{PM}_{2.5}$ and TSP collected inside and outside the Pit No. 1 display hall during winter and summer sampling campaigns from 1993 to 2013 and the tourist numbers, environment-related measures, construction work and indoor activities in Emperor Qin's Terra-cotta Museum since the 1990s are illustrated in Figure 3. The length of the arrowed lines represents the durations of environmental measures that may reduce the source emission of indoor particles (green arrowed lines) and construction work or indoor activities that may increase the level of indoor airborne particulate matter (black arrowed lines). As shown in Figure 3, a significant decrease of indoor particulate matter mass was achieved under the implementation of the environmental policies since the 1990s. Indoor mass concentrations of summer and winter TSP decreased by $68.1 \%$ and $17.9 \%$ from the 1993-1994 campaign to the 2004-2005 campaign, as well as the mass concentrations of indoor $\mathrm{PM}_{2.5}$ during the summer and winter campaigns in 2013 decreased by $39.3 \%$ and $59.3 \%$ compared to those in 2004-2005, respectively. Moreover, the decrease of particle emission from uncovered soil and coal combustion inside the area of QTM and the surrounding area led to a sharp decline of outdoor TSP and PM2.5 mass concentration. 


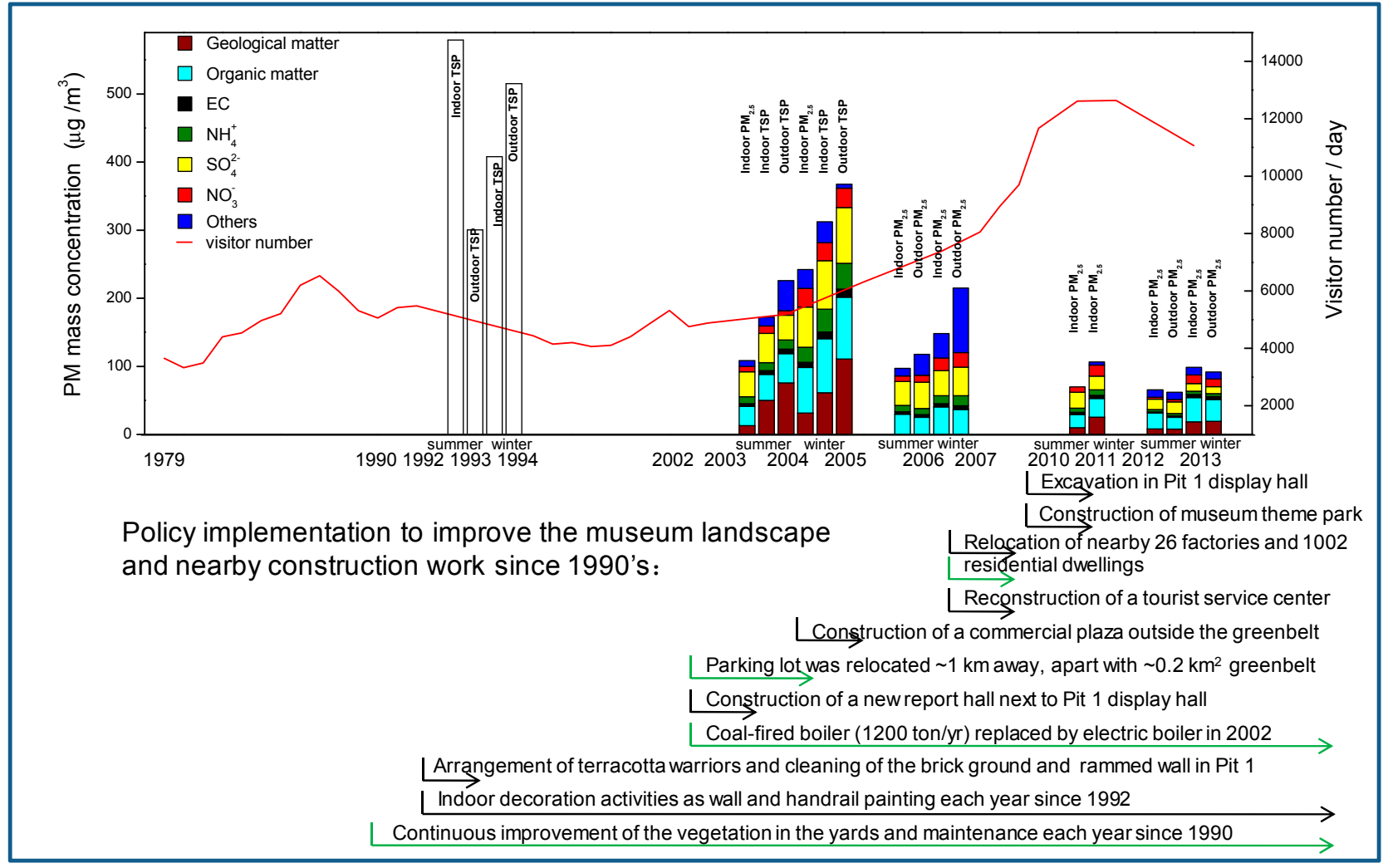

Figure 3. Tourist number, mass concentrations and mass balance of $\mathrm{PM}_{2.5}$ and TSP collected inside and outside the Pit No. 1 display hall during the winter and summer sampling campaigns from 1993 to 2013 and environment-related measures, construction work and indoor activities in Emperor Qin's Terra-cotta Museum since the 1990s. EC, elemental carbon.

The mass concentrations of $\mathrm{PM}_{2.5}$ inside and outside Pit 1, their indoor/outdoor $(\mathrm{I} / \mathrm{O})$ ratios and visitor numbers during the summer and winter sampling days in 2013 are shown in Figure 4. The I/O ratios of $\mathrm{PM}_{2.5}$ mass concentrations ranged from 0.82 to 1.45 with an average of 1.07 in summer and from 0.89 to 1.59 with an average of 1.05 in winter. Since the third excavation campaign started in 2009 and the on-site restoration work started in 2011, dozens of museum staff worked in the rear half of the display hall. Although no significant association between visitor flow and mass concentrations of indoor $\mathrm{PM}_{2.5}$ was found, most of the $\mathrm{I} / \mathrm{O}$ ratios of $\mathrm{PM}_{2.5}$ mass were larger than one, implying that excavation, restoration work and cleaning activities were important airborne particulate sources in Pit 1 besides tourist flow.

The chemical compositions of indoor and outdoor $\mathrm{PM}_{2.5}$ samples collected during the summer and winter campaigns in 2013 are listed in Table 2, and the indoor levels are compared with those measured in the 2004-2005 [17] and 2011 [25] campaigns. Although the summer and winter mass concentrations of indoor $\mathrm{PM}_{2.5}$ in 2013 were lower than those in 2004-2005 and 2011, respectively, the winter to summer ratios of elemental K were 4.7 in 2004-2005, 2.4 in 2011 and 3.0 in 2013, indicating an obvious influence of biomass burning from domestic heating in the wintertime around the museum. In all three sampling campaigns, the most abundant water-soluble ions were sulfate, nitrate and ammonium, suggesting the heavy influence of anthropogenic activities. The sum of the three ions account for $32.7 \%$ and $29.1 \%$ in summer and winter $\mathrm{PM}_{2.5}$ mass in 2013, respectively, lower than those in 2004-2005 
(50.7\% in summer and $44.7 \%$ in winter), implying the benefit from the energy innovation inside the museum and the relocation of the parking lot, factories and residential dwellings in the surrounding area.

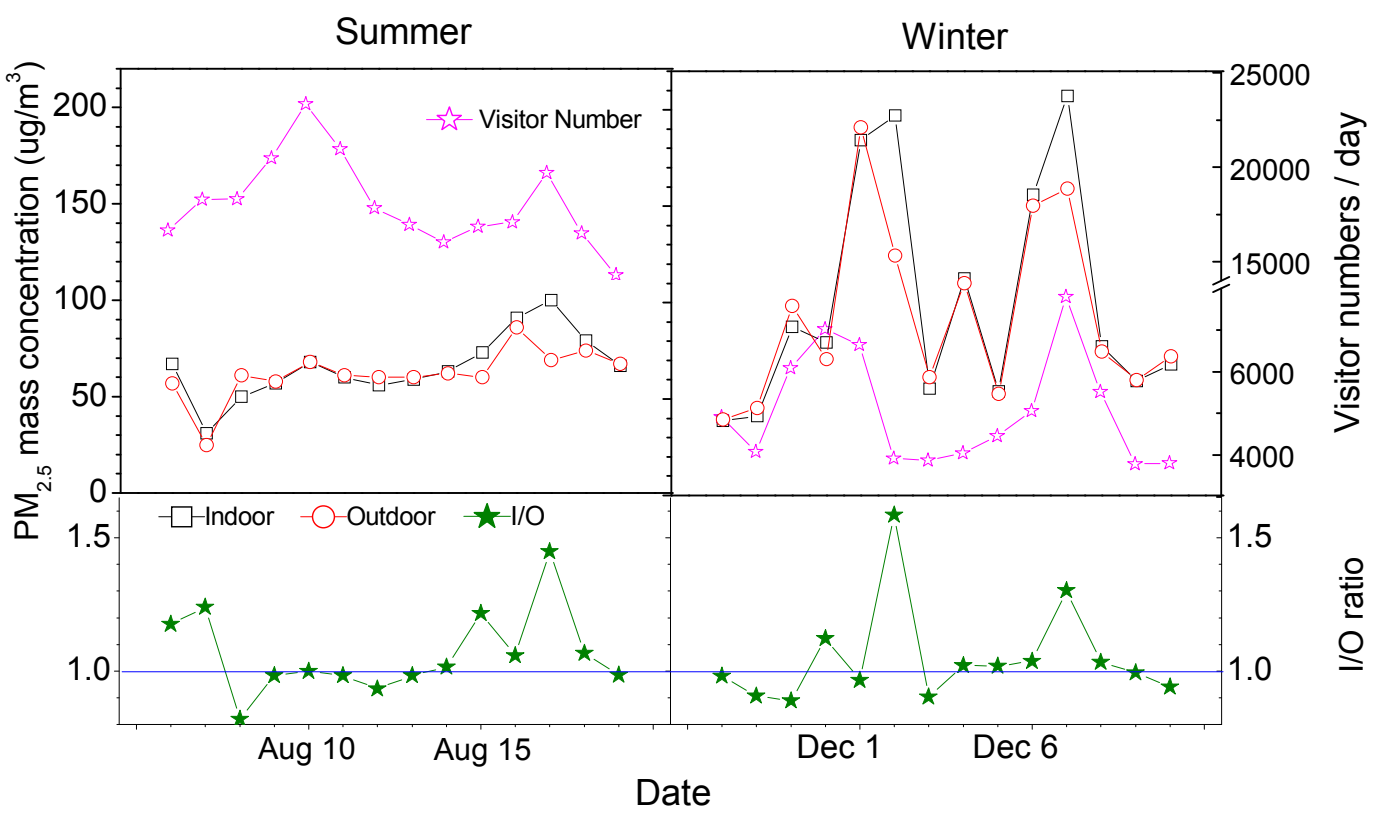

Figure 4. The mass concentrations of $\mathrm{PM}_{2.5}$ inside and outside the Pit No. 1 display hall, their indoor/outdoor $(\mathrm{I} / \mathrm{O})$ ratios and visitor numbers during the summer and winter sampling campaigns in 2013.

The indoor and outdoor mass concentrations of major water-soluble ions related to anthropogenic activities in $\mathrm{PM}_{2.5}$ collected in the 2013 campaigns are shown in Figure 5. Correlation analysis showed that ammonium was strongly correlated with sulfate and nitrate in $\mathrm{PM}_{2.5}$, both in the summer and winter campaigns. Wheat straw and maize stalk are widely used as fuels for domestic cooking and winter heating in suburban Xi'an. A strong relationship between chloride and potassium was also observed during winter $(\mathrm{R}=0.96)$, implying the significant influence of extensive biomass burning from domestic heating in winter around the museum.

Table 2. Statistical summary of indoor and outdoor $\mathrm{PM}_{2.5}$ chemical composition for 24-hour integrated samples acquired over the summer and winter periods in 2004-2005 [17], 2011 [25] and 2013 (in this study) campaigns at the Emperor Qin's Terra-Cotta Museum in Xi'an, China. OC, organic carbon.

\begin{tabular}{|c|c|c|c|c|c|c|c|c|}
\hline & \multicolumn{2}{|c|}{ Indoor $\mathrm{PM}_{2.5}$ (2013) } & \multicolumn{2}{|c|}{ Outdoor $\mathbf{P M}_{2.5}$ (2013) } & \multicolumn{2}{|c|}{ Indoor $\mathrm{PM}_{2.5}$ (2011) } & \multicolumn{2}{|c|}{ Indoor $\mathrm{PM}_{2.5}$ (2004-2005) } \\
\hline & Summer & Winter & Summer & Winter & Summer & Winter & Summer & Winter \\
\hline Mass & $65.7 \pm 17.1$ & $98.6 \pm 58.5$ & $62.1 \pm 13.1$ & $91.9 \pm 45.7$ & $65.7 \pm 31.1$ & $106.5 \pm 58.2$ & $108.4 \pm 30.3$ & $242.3 \pm 189.0$ \\
\hline $\mathrm{OC}$ & $14.6 \pm 3.8$ & $22.2 \pm 11.5$ & $10.9 \pm 2.9$ & $20.1 \pm 9.4$ & $12.0 \pm 3.0$ & $17.0 \pm 4.5$ & $17.6 \pm 2.2$ & $41.7 \pm 27.8$ \\
\hline $\mathrm{EC}$ & $1.7 \pm 0.6$ & $4.7 \pm 3.2$ & $1.9 \pm 0.7$ & $4.0 \pm 2.6$ & $3.2 \pm 1.7$ & $4.5 \pm 1.8$ & $3.9 \pm 0.6$ & $7.7 \pm 5.7$ \\
\hline $\mathrm{NO}_{3}^{-}$ & $2.9 \pm 1.2$ & $12.8 \pm 11.1$ & $3.6 \pm 2$ & $11.5 \pm 8.7$ & $7.9 \pm 6.8$ & $16.3 \pm 13.7$ & $8.0 \pm 4.1$ & $27.2 \pm 20.5$ \\
\hline $\mathrm{SO}_{4}{ }^{2-}$ & $15.2 \pm 6.5$ & $11 \pm 7.4$ & $16.9 \pm 5.9$ & $10.3 \pm 5.3$ & $23.2 \pm 12.1$ & $20.1 \pm 12.5$ & $36.6 \pm 14.5$ & $58.9 \pm 45.0$ \\
\hline $\mathrm{NH}_{4}^{+}$ & $3.4 \pm 1.7$ & $4.8 \pm 4.9$ & $3.7 \pm 1.5$ & $4.3 \pm 4.1$ & $6.5 \pm 4.2$ & $8.1 \pm 5.7$ & $10.3 \pm 4.6$ & $22.3 \pm 17.9$ \\
\hline
\end{tabular}


Table 2. Cont.

\begin{tabular}{|c|c|c|c|c|c|c|c|c|}
\hline & \multicolumn{2}{|c|}{ Indoor $\mathrm{PM}_{2.5}$ (2013) } & \multicolumn{2}{|c|}{ Outdoor $\mathrm{PM}_{2.5}$ (2013) } & \multicolumn{2}{|c|}{ Indoor $\mathrm{PM}_{2.5}$ (2011) } & \multicolumn{2}{|c|}{ Indoor $\mathrm{PM}_{2.5}$ (2004-2005) } \\
\hline & Summer & Winter & Summer & Winter & Summer & Winter & Summer & Winter \\
\hline $\mathrm{Ca}^{2+}$ & $1.1 \pm 0.4$ & $1.4 \pm 0.5$ & $1.2 \pm 0.4$ & $1.5 \pm 0.5$ & $1.7 \pm 0.5$ & $1.8 \pm 0.5$ & $1.5 \pm 0.4$ & $2.2 \pm 1.9$ \\
\hline $\mathrm{K}^{+}$ & $0.5 \pm 0.2$ & $1.3 \pm 0.9$ & $0.5 \pm 0.2$ & $1.1 \pm 0.6$ & $1.0 \pm 0.6$ & $2.1 \pm 1.2$ & $1.1 \pm 0.4$ & $3.8 \pm 2.4$ \\
\hline K & $0.4 \pm 0.2$ & $1.2 \pm 0.7$ & $0.4 \pm 0.2$ & $1.1 \pm 0.5$ & $1 \pm 0.7$ & $2.4 \pm 1.3$ & $0.9 \pm 0.4$ & $4.2 \pm 3.0$ \\
\hline $\mathrm{Ti}$ & $16.8 \pm 11.2$ & $42.5 \pm 13.5$ & $17.2 \pm 10.2$ & $47.4 \pm 15$ & $19.4 \pm 12.5$ & $65.8 \pm 33.3$ & $65.2 \pm 21.4$ & $162.7 \pm 190.3$ \\
\hline V & $0.2 \pm 0.8$ & $1.4 \pm 1.8$ & $1.3 \pm 2.4$ & $0.9 \pm 1.2$ & $1 \pm 1.3$ & $1.5 \pm 2$ & $4.4 \pm 3.5$ & $13.3 \pm 10.5$ \\
\hline $\mathrm{Mn}$ & $28.4 \pm 10.3$ & $51.6 \pm 19.2$ & $28.1 \pm 11.5$ & $49.1 \pm 23.1$ & $26.2 \pm 16.7$ & $62.2 \pm 36.1$ & $35.5 \pm 13.5$ & $104.3 \pm 66.3$ \\
\hline $\mathrm{Fe}$ & $285.2 \pm 115.8$ & $650.2 \pm 181$ & $274.7 \pm 141.4$ & $680.7 \pm 193.5$ & $346.7 \pm 160.4$ & $897.1 \pm 435.1$ & $459.3 \pm 136.9$ & $1105.8 \pm 1447.9$ \\
\hline $\mathrm{Ni}$ & $1.2 \pm 2$ & $1.8 \pm 2.7$ & $0.6 \pm 1$ & $0.1 \pm 0.4$ & $4 \pm 2.2$ & $4.8 \pm 1.9$ & $6.4 \pm 5.9$ & $13.1 \pm 12.6$ \\
\hline $\mathrm{Cu}$ & $6.5 \pm 3.6$ & $16.2 \pm 7.5$ & $6 \pm 4.2$ & $13.8 \pm 5.9$ & $10.4 \pm 4.7$ & $22.7 \pm 9.6$ & $7.3 \pm 2.1$ & $5.3 \pm 2.6$ \\
\hline $\mathrm{Zn}$ & $207.6 \pm 114.1$ & $503.9 \pm 298.2$ & $231.1 \pm 150.1$ & $450.8 \pm 259.9$ & $334.1 \pm 213.4$ & $484.1 \pm 268.2$ & $305.0 \pm 183.8$ & $603.3 \pm 581.1$ \\
\hline As & $7.3 \pm 8.6$ & $8.8 \pm 12.3$ & $4.3 \pm 7.7$ & $8.2 \pm 10.9$ & $5.3 \pm 9.7$ & $32.7 \pm 43.8$ & $19.8 \pm 6.1$ & $63.2 \pm 55.2$ \\
\hline $\mathrm{Br}$ & $3.7 \pm 3.2$ & $14.1 \pm 13$ & $5.1 \pm 4.7$ & $10.3 \pm 10.1$ & $9.1 \pm 7.3$ & $17.2 \pm 8$ & $14.1 \pm 13.6$ & $34.7 \pm 30.8$ \\
\hline $\mathrm{Sr}$ & $6.5 \pm 12.2$ & $1 \pm 2.7$ & $4.9 \pm 12.6$ & $3.7 \pm 5.6$ & $7.7 \pm 3.9$ & $20.9 \pm 13.1$ & $10.3 \pm 9.7$ & $24.8 \pm 21.2$ \\
\hline $\mathrm{Pb}$ & $47.2 \pm 27.7$ & $126.6 \pm 61.8$ & $62.5 \pm 36.8$ & $109.5 \pm 48.3$ & $98 \pm 49.3$ & $267.7 \pm 179.9$ & $154.0 \pm 75.2$ & $461.0 \pm 312.8$ \\
\hline
\end{tabular}

Units: from mass to $\mathrm{K}, \mu \mathrm{g} / \mathrm{m}^{3}$; from $\mathrm{Ti}$ to $\mathrm{Pb}, \mathrm{ng} / \mathrm{m}^{3}$.

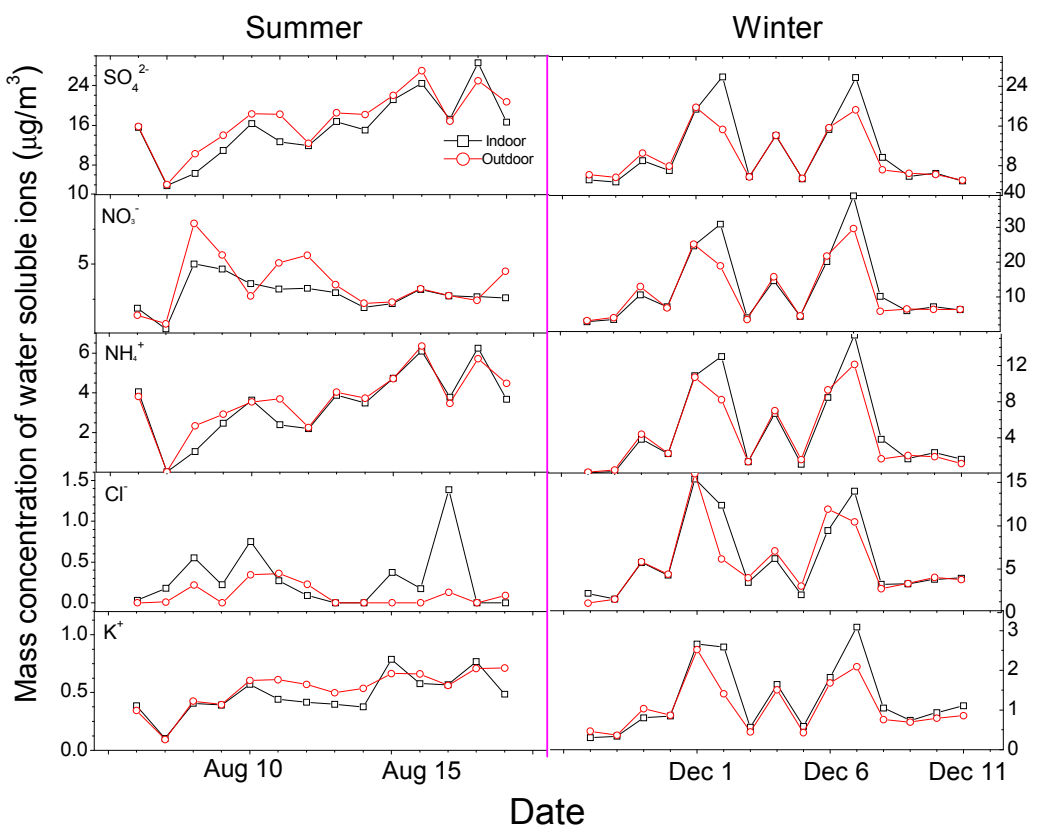

Figure 5. The mass concentrations of major water-soluble ions in $\mathrm{PM}_{2.5}$ inside and outside the Pit No. 1 display hall during the summer and winter sampling campaigns in 2013.

The charge balance between cation and anion was calculated using Equations (1) and (2). The correlations between cation and anion are summarized in Table 3.

$$
\begin{gathered}
\text { Cation equivalence }=\frac{\mathrm{Na}^{+}}{23}+\frac{\mathrm{NH}_{4}^{+}}{18}+\frac{\mathrm{K}^{+}}{39}+\frac{\mathrm{Mg}^{2+}}{12}+\frac{\mathrm{Ca}^{2+}}{20} \\
\text { Anion equivalence }=\frac{\mathrm{Cl}^{-}}{35.5}+\frac{\mathrm{NO}_{3}^{-}}{62}+\frac{\mathrm{SO}_{4}^{2-}}{48}
\end{gathered}
$$


Table 3. Cation and anion balance in indoor $\mathrm{PM}_{2.5}$ samples collected during several seasonal sampling campaigns from 2004 to 2013 [17,24,25].

\begin{tabular}{cccccc}
\hline Date & \multicolumn{2}{c}{ Summer } & & Winter & Reference \\
\hline 2013 & A.E. $=1.28$ C.E. +0.03 & $\mathrm{R}^{2}=0.97$ & A.E. $=1.41$ C.E. +0.004 & $\mathrm{R}^{2}=0.99$ & This study \\
2011 & A.E. $=1.22$ C.E. -0.16 & $\mathrm{R}^{2}=0.98$ & A.E. $=1.27$ C.E. -0.22 & $\mathrm{R}^{2}=0.99$ & {$[25]$} \\
$2006-2007$ & A.E. $=1.21$ C.E. -0.27 & $\mathrm{R}^{2}=0.69$ & A.E. $=1.21$ C.E. -0.37 & $\mathrm{R}^{2}=0.96$ & {$[24]$} \\
$2004-2005$ & A.E. $=1.38$ C.E. -0.05 & $\mathrm{R}^{2}=0.98$ & A.E. $=1.08$ C.E. +0.08 & $\mathrm{R}^{2}=1.0$ & {$[17]$} \\
\hline
\end{tabular}

Notes: A.E. refers to anion equivalence; C.E. refers to cation equivalence.

The cation and anion concentrations measured for indoor $\mathrm{PM}_{2.5}$ in all four campaigns have a correlation coefficient $\left(\mathrm{R}^{2}\right)$ greater than 0.9 , suggesting the same origin for ions in indoor $\mathrm{PM}_{2.5}$. Most of the slopes of indoor $\mathrm{PM}_{2.5}$ were all larger than 1.2, both in summer and in winter, indicating that the suspended fine particles inside the Pit No. 1 display hall were acidic [31]. Although the acidic secondary inorganic species, such as sulfate and nitrate, in indoor PM2.5 decreased from 2004-2005 to 2013 and the concurrent percentage of geological materials increased slightly due to the excavation activity and tourist flow, excess sulfuric and nitric acidic particles were not neutralized in the atmosphere. Those acidic particles inside the museum could deposit onto the surface of statues and pose corrosion and salt weathering hazards to the statues.

The sulfur oxidation ratio was defined as $\mathrm{SOR}=n-\mathrm{SO}_{4}{ }^{2-} /\left(n-\mathrm{SO}_{4}{ }^{2-}+n-\mathrm{SO}_{2}\right)$, and the nitrogen oxidation ratio was defined as $\mathrm{NOR}=n-\mathrm{NO}_{3}{ }^{-} /\left(n-\mathrm{NO}_{3}{ }^{-}+n-\mathrm{NO}_{2}\right)$, where $n$ is the number of moles. SOR and NOR could reflect the degree of the secondary transformation processes in the atmosphere. In primary emissions, the SOR is typically less than 0.10 [32,33], and SOR larger than 0.10 occurs by photochemical oxidation of $\mathrm{SO}_{2}$ [34]. The SOR and NOR inside and outside Pit 1 during the summer and winter sampling campaigns from 2006 to 2013 are listed in Table 4. All of the SORs and NORs are higher than 0.10 during the summer and winter campaigns in 2006 and 2013, showing that indoor and outdoor atmospheric $\mathrm{SO}_{2}$ and $\mathrm{NO}_{2}$ had been photochemical oxidized. Higher SORs were observed in summer, implying that the sulfation reaction was favored by higher temperature, high relative humidity and strong solar radiation. Moreover, a high concentration of ammonia in summer might also accelerate the secondary conversion [35].

Table 4. Sulfur oxidation ratio (SOR) and nitrogen oxidation ratio (NOR) inside and outside the Pit No. 1 Display Hall of Emperor Qin's Terra-cotta Museum during the summer and winter sampling campaigns from 2006 [24] to 2013.

\begin{tabular}{cccccc}
\hline & \multicolumn{2}{c}{ SOR } & & \multicolumn{2}{c}{ NOR } \\
\cline { 2 - 3 } \cline { 5 - 6 } & Indoor & Outdoor & & Indoor & Outdoor \\
\hline Summer 2013 & 0.48 & 0.53 & & 0.13 & 0.13 \\
Winter 2013 & 0.26 & 0.12 & & 0.14 & 0.14 \\
Summer 2006 & 0.53 & 0.60 & & 0.41 & 0.57 \\
Winter 2006 & 0.43 & 0.39 & & 0.33 & 0.34 \\
\hline
\end{tabular}

The $\mathrm{I} / \mathrm{O}$ ratios for the mass concentrations of $\mathrm{PM}_{2.5}$ and its major components during the summer and winter campaigns in 2013 are illustrated in Figure 6. By comparing those I/O ratios obtained in the 2004-2005 campaign, the significant influences of indoor activities were observed. Most of the I/O 
ratios were larger than 1.0 in Pit 1, including $\mathrm{PM}_{2.5}$ mass, geological matter, organic matter and elemental carbon, due to the increased tourist flow and human activities at the archaeological site. The summer I/O ratio of organic matter was the highest in 2013, reaching 1.35 in the summer, probably owing to the evaporation of the alcohol solvent and resin adhesive used in the excavation and restoration works. The I/O ratios of sulfate, nitrate and ammonium were lower in 2013 than those in 2004-2005, implying less formation of secondary inorganic aerosols with the indoor RH decreasing in recent years.

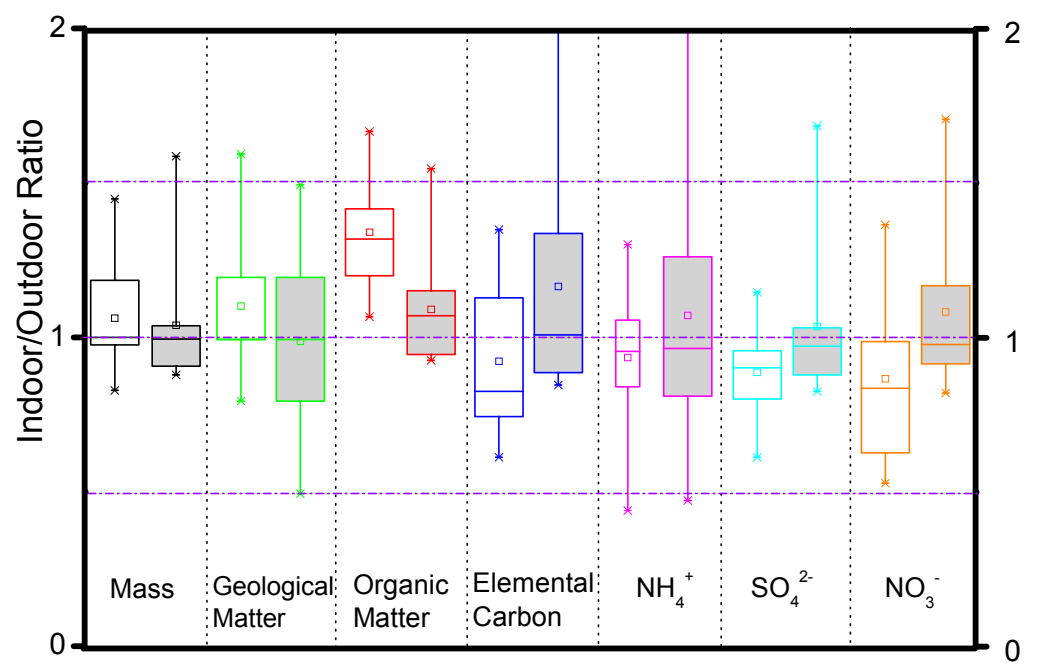

Figure 6. I/O ratios for $\mathrm{PM}_{2.5}$ mass and its major components during the summer (empty boxes) and winter (shade boxes) campaigns in 2013.

\subsection{Acidic Gaseous Pollutants}

The indoor and outdoor concentrations of acidic gaseous pollutants in Pit 1 of the QTM during the summer and winter sampling campaigns from 1993 to 2013 are summarized in Table 5. The concentrations of $\mathrm{SO}_{2}$ and $\mathrm{NO}_{2}$ were higher in winter than those in summer during all sampling campaigns, indicating the emission from combustion for winter heating. In the past 20 years, the outdoor $\mathrm{SO}_{2}$ slightly decreased due to the energy innovation and relocation of combustion sources. The concentration of indoor $\mathrm{NO}_{2}$ increased in 2013 compared to those in 1993-1994, probably due to the increase of the visitor number and heavy traffic around the museum.

Table 5. The concentrations of acidic gaseous pollutants inside and outside the Pit No. 1 Display Hall of Emperor Qin's Terra-cotta Museum during the summer and winter sampling campaigns from 1993 to 2013.

\begin{tabular}{ccccc}
\hline Date & Site & $\mathbf{S O}_{2}$ & $\mathbf{N O}_{2}$ & Reference \\
\hline Summer & & & & \\
\hline August 2013 & Indoor & $4.6 \pm 1.3$ & $16.2 \pm 6.2$ & This study \\
August 2006 & Indoor & $7.0 \pm 1.4$ & $4.5 \pm 1.6$ & {$[24]$} \\
August 1993 & Indoor & 6.3 & 7.8 & {$[23]$} \\
August 2013 & Outdoor & $6.0 \pm 6.5$ & $18.0 \pm 8.0$ & This study \\
August 2006 & Outdoor & $8.2 \pm 1.2$ & $3.9 \pm 1.1$ & {$[24]$} \\
August 1993 & Outdoor & 26.3 & 11.7 & {$[23]$} \\
\hline
\end{tabular}


Table 5. Cont.

\begin{tabular}{ccccc}
\hline Date & Site & $\mathbf{S O}_{2}$ & $\mathbf{N O}_{2}$ & Reference \\
\hline Winter & & & & \\
\hline November-December 2013 & Indoor & $27.0 \pm 11.9$ & $18.9 \pm 4.5$ & This study \\
December 2006 & Indoor & $13.1 \pm 3.1$ & $13.1 \pm 3.9$ & {$[24]$} \\
January 1994 & Indoor & 11.2 & 10.2 & {$[23]$} \\
November-December 2013 & Outdoor & $33.6 \pm 17.1$ & $24.1 \pm 5.6$ & This study \\
December 2006 & Outdoor & $19.4 \pm 3.6$ & $15.8 \pm 4.5$ & {$[24]$} \\
January 1994 & Outdoor & 44.8 & 16.1 & {$[23]$} \\
\hline
\end{tabular}

\section{Conclusions}

In this study, the results of long-term indoor air quality measurement from 1989 to 2013 were summarized to evaluate the influence of environmental policy and indoor activities on the potential hazards to the priceless and irreplaceable statues in QTM. The poor air tightness and thermal performance of the building envelope of Pit 1 resulted in the sharp changes in microclimate conditions for more than 20 years. With the dramatic decrease of indoor PM mass and multiplied tourist flow and restoration work during the past 10 years, the influence of indoor activities on the mass concentration and chemical composition of indoor suspended particulate matter should be of increasing concern. Remedial measures, as extensive as renovation of the building's structure and an effective ventilation and filtration system and some less extensive measures, such as protective devices, proper floor coverings, cleaning and display strategies, should be adopted to reduce the fluctuation of microclimate conditions and the influence of indoor activities on suspended particles.

\section{Acknowledgments}

This work was supported in part by the National Key Technology R\&D Program (2012BAK14B01), State Administration of Cultural Heritage Project (20120219) and the Natural Science Foundation of China (NSFC 41271480).

\section{Author Contributions}

Junji Cao, Tafeng Hu, Rujin Huang and Tao Ma conceptualized, designed and implemented the project. Hua Li, Wenting Jia, Suixin Liu and $\mathrm{Na}$ Xi performed the experiments and data collections. The manuscript was drafted by Hua Li and Tafeng Hu.

\section{Conflicts of Interest}

The authors declare no conflict of interest.

\section{References}

1. Thomson, G. Air pollution-A review for conservation chemists. Stud. Conserv. 1965, 10, $147-167$. 
2. Baer, N.S.; Banks, P.N. Indoor air pollution: Effects on cultural and historical materials. Int. J. Mus. Mgmt. Cur. 1985, 4, 9-20.

3. Brimblecombe, P. The composition of museum atmospheres. Atmos. Environ. 1990, 24, 1-8.

4. Nazaroff, W.W.; Salmon, L.G.; Cass, G.R. Concentration and fate of airborne particles in museums. Environ. Sci. Technol. 1990, 24, 66-77.

5. Brimblecombe, P.; Blades, N.; Camuffo, D.; Sturaro, G.;Valentino, A.; Gysels, K.; van Grieken, R.; Busse, H.J.; Kim, O.; Ulrych, U.; et al. The indoor environment of a modern museum building, the Sainsbury Centre for Visual Arts, Norwich, UK. Indoor Air 1999, 9, 146-164.

6. Oddy, W.A. Chemistry in the conservation of archaeological materials. Sci. Total Environ. 1994, $143,121-126$.

7. De Bock, L.A.; van Grieken, R.E.; Camuffo, D.; Grime, G.W. Microanalysis of museum aerosols to elucidate the soiling of paintings: Case of the Correr Museum, Venice, Italy. Environ. Sci. Technol. 1996, 30, 3341-3350.

8. Ligocki, M.P.; Liu, H.I.H.; Cass, G.R.; John, W. Measurements of particle deposition rates inside Southern California Museums. Aerosol Sci. Technol. 1990, 13, 85-101.

9. Gysels, K.; Deutsch, F.; Grieken, R.V. Characterisation of particulate matter in the Royal Museum of Fine Arts, Antwerp, Belgium. Atmos. Environ. 2002, 36, 4103-4113.

10. Camuffo, D.; Brimblecombe, P.; van Grieken, R.; Busse, H.J.; Sturaro, G.; Valentino, A.; Bernardi, A.; Blades, N.; Shooter, D.; de Bock, L.; et al. Indoor air quality at the Correr Museum, Venice, Italy. Sci. Total Environ. 1999, 236, 135-152.

11. Worobiec, A.; Samek, L.; Karaszkiewicz, P.; Kontozova-Deutsch, V.; Stefaniak, E.A.; van Meel, K.; Krata, A.; Bencs, L.; van Grieken, R.A. Seasonal study of atmospheric conditions influenced by the intensive tourist flow in the Royal Museum of Wawel Castle in Cracow, Poland. Microchem. J. 2008, 90, 99-106.

12. Grosjean, D.; Salmon, L.G.; Cass, G.R. Fading of organic artists' colorants by atmospheric nitric acid: Reaction products and mechanisms. Environ. Sci. Technol. 1992, 26, 952-959.

13. Cao, J.J. Pollution status and control strategies of $\mathrm{PM}_{2.5}$ in China. J. Earth Environ. 2012, 3, 1030-1036. (In Chinese)

14. Christoforou, C.S.; Salmon, L.G.; Cass, G.R. Fate of atmospheric particles within the Buddhist Cave Temples at Yungang, China. Environ. Sci. Technol. 1996, 30, 3425-3434.

15. Christoforou, C.S.; Salmon, L.G.; Cass, G.R. Passive filtration of airborne particles from buildings ventilated by natural convection: Design procedures and a case study at the Buddhist Cave Temples at Yungang, China. Aerosol Sci. Technol. 1999, 30, 530-544.

16. Cao, J.J.; Rong, B.; Lee, S.C.; Chow, J.C.; Ho, K.F.; Liu, S.X.; Zhu, C.S. Composition of indoor aerosols at Emperor Qin's Terra-cotta Museum, Xi'an, China, during summer, 2004. China Particuol. 2005, 3, 170-175.

17. Cao, J.J.; Li, H.; Chow, J.C.; Watson, J.G.; Lee, S.C.; Rong, B.; Dong, J.G.; Ho, K.F. Chemical composition of indoor and outdoor atmospheric particles at Emperor Qin's Terra-cotta Museum, Xi'an, China. Aerosol Air Qual. Res. 2011, 11, 70-79. 
18. Hu, T.F.; Lee, S.C.; Cao, J.J.; Chow, J.C.; Watson, J.G.; Ho, K.F.; Ho, W.K.; Rong, B.; An, Z.S. Characterization of winter airborne particles at Emperor Qin's Terra-cotta Museum, China. Sci. Total Environ. 2009, 407, 5317-5327.

19. Hu, T.F.; Cao, J.J.; Ho, K.F.; An, Z.S.; Lee, S.C.; Chow, J.C.; Watson, J.G. ; Li, H. Winter and summer characteristics of airborne particles inside Emperor Qin's Terra-Cotta Museum, China: A study by scanning electron microscopy-energy dispersive X-ray spectrometry. J. Air Waste Manag. 2011, 61, 914-922,

20. Huang, R.J.; Zhang, Y.; Bozzetti, C.; Ho, K.F.; Cao, J.J.; Han, Y.M. High secondary aerosol contribution to particulate pollution during haze events in China. Nature 2014, 514, 218-222.

21. Cao, J.J. PM2.5 and Environment; Science Press: Beijing, China, 2014. (In Chinese)

22. Emperor Qin Shihuang's Mausoleum Site Museum Committee. Yearbook of Emperor Qin's Terra-Cotta Museum; Emperor Qin Shihuang's Mausoleum Site Museum: Xi'an, China, 1990-2013. (In Chinese)

23. Zhang, Z.J. Study on Environmental Quality of Emperor Qin's Terra-Cotta Museum; Shaanxi People Press: Xi'an, China, 1998. (In Chinese)

24. Dong, J.G. The Physical and Chemical Characteristics and Source Appointment of Indoor Aerosols at Emperor Qin's Terra-Cotta Museum, Xi'an, China. Ph.D. Thesis, Institute of Earth Environment, CAS, Xi'an, China, 2007. (In Chinese)

25. Li, H.; Wang, W.J.; Zhao, F.Y.; Wang, C.Y.; Li, B.; Feng, L. Passive sampling and Ion Chromatography measurement of corrosive gases in Emperor Qin's Terracotta Warriors and Horses Museum. Sci. Conserv. Archaeol 2014, 4, 54-61.

26. Xu, H.M.; Cao, J.J.; Ho, K.F.; Ding, H.; Han, Y.M.; Wang, G.H.; Chow, J.C.; Watson, J.G.; Khol, S.D.; Qiang, J.; et al. Lead concentrations in fine particulate matter after the phasing out of leaded gasoline in Xi' an, China. Atmos. Environ. 2012, 46, 217-224.

27. Chow, J.C.; Watson, J.G. Ion chromatography in elemental analysis of airborne particles. In Elemental Analysis of Airborne Particles; Landsberger, S., Creatchman, M., Eds.; Gordon and Breach Science: Amsterdam, The Netherlands, 1999; pp. 97-137.

28. Cao, J.J.; Lee, S.C.; Ho, K.F.; Zhang, X.Y.; Zhu, S.C.; Fung, K.; Chow, J.C.; Watson, J.G. Characteristics of carbonaceous aerosol in Pearl River Delta Region, China during 2001 winter period. Atmos. Environ. 2003, 37, 1451-1460.

29. Jin, L.; Wang, J.; Zhang, H. Comparative analysis on temperature changes in city and suburbs of Xi'an over the past 40 Years. J. Arid Meteorol. 2013, 4, 720-725.

30. ASHRAE Handbook Committee. 2007 ASHRAE Handbook-Heating, Ventilating, and Air-Conditioning Applications; ASHRAE: Atlanta, GA, USA, 2007.

31. Kerminen, V.M.; Hillamo, R.; Teinilä, K.; Pakkanen, T.; Allegrini, I.; Sparapani, R. Ion balances of size-resolved tropospheric aerosol samples: Implications for the acidity and atmospheric processing of aerosols. Atmos. Environ. 2001, 35, 5255-5265.

32. Pierson, W.R.; Brachaczek, W.W.; McKee, D.E. Sulfate emissions from catalyst equipped automobiles on the highway. J. Air Pollut. Control Assoc. 1979, 29, 255-257. 
33. Truex, T.J.; Pierson, W.R.; McKee, D.E. Sulfate in diesel exhaust. Environ. Sci. Technol. 1980, 14, 1118-1121.

34. Ohta, S.; Okita, T.A. Chemical characterization of atmospheric aerosol in Sapporo. Atmos. Environ. 1990, 24, 815-822.

35. Cao, J.J.; Zhang, T.; Chow, J.C.; Watson, J.G.; Wu, F.; Li, H. Characterization of atmospheric ammonia over Xi'an, China. Aerosol Air Qual. Res. 2009, 9, 277-289.

(C) 2015 by the authors; licensee MDPI, Basel, Switzerland. This article is an open access article distributed under the terms and conditions of the Creative Commons Attribution license (http://creativecommons.org/licenses/by/4.0/). 